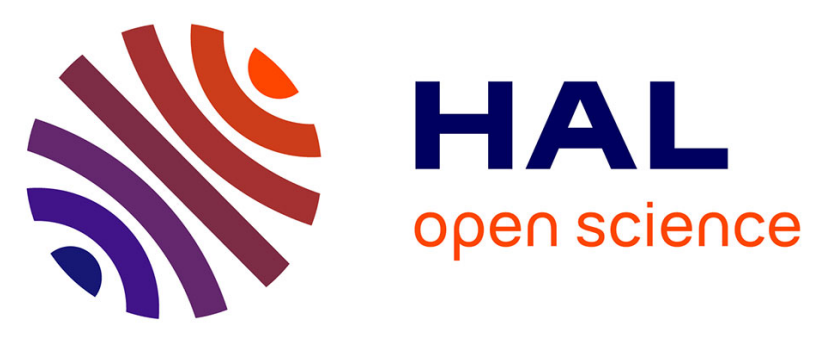

\title{
Accelerating and Stabilizing the Vapor-Liquid Equilibrium (VLE) Calculation in Compositional Simulation of Unconventional Reservoirs Using Deep Learning Based Flash Calculation
}

Shihao Wang, Nicolas Sobecki, Didier Ding, Lingchen Zhu, Yu-Shu Wu

\section{To cite this version:}

Shihao Wang, Nicolas Sobecki, Didier Ding, Lingchen Zhu, Yu-Shu Wu. Accelerating and Stabilizing the Vapor-Liquid Equilibrium (VLE) Calculation in Compositional Simulation of Unconventional Reservoirs Using Deep Learning Based Flash Calculation. Fuel, 2019, 253, pp.209-219. 10.1016/j.fuel.2019.05.023 . hal-02142339

\section{HAL Id: hal-02142339 \\ https://hal-ifp.archives-ouvertes.fr/hal-02142339}

Submitted on 28 May 2019

HAL is a multi-disciplinary open access archive for the deposit and dissemination of scientific research documents, whether they are published or not. The documents may come from teaching and research institutions in France or abroad, or from public or private research centers.
L'archive ouverte pluridisciplinaire HAL, est destinée au dépôt et à la diffusion de documents scientifiques de niveau recherche, publiés ou non, émanant des établissements d'enseignement et de recherche français ou étrangers, des laboratoires publics ou privés. 
1 Accelerating and Stabilizing the Vapor-Liquid Equilibrium (VLE) Calculation in Compositional 2 Simulation of Unconventional Reservoirs Using Deep Learning Based Flash Calculation

Shihao Wang ${ }^{1}$, Nicolas Sobecki ${ }^{2}$, Didier Ding ${ }^{2}$, Lingchen Zhu $^{3}$, Yu-Shu Wu ${ }^{1}$

${ }^{1}$ Petroleum Engineering Department, Colorado School of Mines, Golden, CO 80401, USA

${ }^{2}$ IFPEN, France

${ }^{3}$ Schlumberger Doll Research Center, Cambridge, MA 02139, USA

\section{Abstract}

The flash calculation with large capillary pressure often turns out to be time-consuming and unstable. Consequently, the compositional simulation of unconventional oil/gas reservoirs, where large capillary pressure exists on the vapor-liquid phase interface due to the narrow pore channel, becomes a challenge to traditional reservoir simulation techniques. In this work, we try to resolve this issue by combining deep learning technology with reservoir simulation. We have developed a compositional simulator that is accelerated and stabilized by stochastically-trained proxy flash calculation.

We first randomly generated 300,000 data samples from a standalone physical flash calculator. We have constructed a two-step neural network, in which the first step is the classify the phase condition of the system and the second step is to predict the concentration distribution among the determined phases. Each network consists of four hidden layers in between the input layer and the output layer. The network is trained by Stochastic Gradient Descent (SGD) method with 100 epochs.

With given temperature, pressure, feed concentration pore radius, the trained network predicts the phases and concentration distribution in the system with very low computational cost. Our results show that the accuracy of the network is above $97 \%$ in the metric of mean absolute percentage error. The predicted result is used as the initial guess of the flash calculation module in the reservoir simulator. With the implementation of the deep learning based flash calculation module, the speed of the simulator has been effectively increased and the stability (in the manner of the ratio of convergence) has been improved as well.

\section{Keywords}

Flash calculation; unconventional reservoirs; deep learning; proxy calculation; reservoir simulation

\section{Introduction}

The oil and gas stored in unconventional reservoirs has some unique transport mechanism and phase behavior, including the pore confine effect [1,2], the large capillary pressure effect $[3,4]$, multiscale pore structures [5] and gas slippage effect [6-9]. Moreover, the prediction of the complex 
phase behaviors in unconventional reservoirs requires compositional modeling, of which the flash calculation is an essential yet time-consuming portion. To improve the speed as well as the stability of the flash calculation, several techniques have been adopted, including reduction method [10], phase stability test [11] and so on. Recently, the fast-arising artificial intelligence (AI) techniques have drawn the attention of researchers. Particularly, the fast development of the optimization algorithm, as well as hardware infrastructure, have greatly promoted the advance of stochastic learning techniques. The rapid development of GPU enables the training of deep learning (DL) networks (also known as Artificial Neural Network (ANN)) [12]. There are several trials of combining Al with flash calculation. Gaganis et al. $[13,14]$ are among the first to propose the application of neural network approach in developing proxy flash calculation. In their work, support vector classifier (SVC) is used to conduct phase stability test and a single layer ANN network is used to replace the physical flash calculation for liquid-vapor phase equilibrium calculation. Kashinath et al. [15] further improved Gaganis et al.'s model by bringing out a novel framework to conduct an isothermal flash calculation. In their work, the relevance vector machine [16] is combined with an single-layer artificial neural network. The former technique is used to classify phase condition, while the latter is used to determine the concentration distribution. All these proxy models have shown sound accuracy and have been successfully implemented into reservoir simulators, improving the speed of compositional simulation. Moreover, El-Sebakhy [17] and RafieeTaghanaki et al. [18] used the support vector machine technique [19-22] to predict the PVT properties of crude oil, including gas oil ratio, oil volume factor, density and so on. Artificial neural networks have also been used to predict the PVT behavior of crude oil [23] and gas mixtures [24]. Nikravesh et al. [25] reviewed the applications of artificial intelligence techniques in the exploration and development of petroleum reservoirs.

In this work, we further extend the work listed above to the compositional simulation of unconventional reservoirs with large capillary pressure effect. We have developed a deep-learning based flash calculation module (proxy flash calculation) for the prediction of phase behaviors of oil and gas in unconventional reservoirs. This proxy flash calculation adopts multi-layer fully connected layers to regress the training data. The input parameters of our model include pressure, temperature, feed concentration and pore radius. The accuracy of the network is above $97 \%$ in the metric of mean absolute percentage error. The proxy flash calculation module is used as a preconditioner of the physical flash calculation and has been implemented in a reservoir simulator. We have also compared the performance of the network with different number of hidden layers. The novelty of this work lies in the implementation of the deep learning based flash calculation module as a preconditioner for both phase condition detection and concentration determination, which improves the speed as well as the stability of compositional simulation of unconventional reservoirs while maintaining the same results as physical flash calculation. 
This paper is organized as follows. In Chapter 2, we present the physical flash calculation used to train the network. In Chapter 3, we describe the structure, training as well as results of our deeplearning based flash calculation module. In Chapter 4, we describe the implementation of the developed module into an in-house reservoir simulator. In Chapter 5 , we present the results of field scale reservoir simulation. In Chapter 6, we summarize and conclude this work.

\section{Forward modeling}

In this section, we briefly introduce the governing equations and flash calculation module used for the forward modeling.

\subsection{Flow governing equations}

The reservoir simulator used in this work is named as MSFLOW_CO2 [3,26,27]. MSFLOW_CO2 is a general three-dimensional reservoir simulator for the simulation of complex multiphase flow in porous media. Based on the law of mass conservation, the flow governing equations of MSFLOW_CO2 describe the transport of hydrocarbon components in a petroleum reservoir. For a vapor-liquid compositional system with $N_{C}$ components, the mass conservation equation for component $k$ is as below

$\frac{\partial}{\partial t}\left(\phi \sum_{\beta} S_{\beta} \rho_{\beta} x_{\beta}^{k}\right)=\nabla \cdot\left[-K_{a} \frac{K_{r \beta} \rho_{\beta}}{\mu_{\beta}}\left(\nabla P_{\beta}-\rho_{\beta} \vec{g}\right) x_{\beta}^{k}\right]+q^{k}, \quad \beta=L, G, \quad k=1, . ., N_{C}$

where $\phi$ is the rock porosity. $\beta$ is the phase index referring to the liquid (L) or vapor/gas (G) phase. $S_{\beta}$ and $\rho_{\beta}$ are the saturation and density of phase $\beta$, respectively. $K_{r \beta}, \mu_{\beta}$ and $P_{\beta}$ are the relative permeability, viscosity and pressure of phase $\beta$, respectively. $K_{a}$ is the apparent permeability. While for the liquid phase, $K_{a}$ is the same as the rock absolute permeability $K_{\infty}$, for the vapor phase, $K_{a}=$ $K_{\infty}(1+b / p)$, in which $b$ is the Klinkenberg parameter. $x_{\beta}^{k}$ is the mole concentration of component $k$ in phase $\beta . \vec{g}$ is the gravity term and $q$ is the sink/source term. In this work the pore compressibility is temporally ignored.

In MSFLOW_CO2, Equation 1 is discretized and solved by the Integrated Finite Difference (IFD) method, the details of which can be found in Ref. [28]. The flow between the rock matrix and the fracture system is described by the dual-porosity model [29]. The nonlinear system resulted from the discritization of IFD is solved by Newton-Raphson's approach. Within each nonlinear iteration, the resulted linear system is solved by a multiscale linear solver [30]. 


\subsection{Flash calculation with capillary pressure}

In a compositional reservoir simulator, given the pressure $(P)$, temperature $(T)$ and mole concentration of each component $\left(z_{i}\right)$, the flash calculation module predicts the phase condition as well as the concentration of each component in each phase.

In this work, we consider a two-phase system with vapor $(V)$ and liquid $(L)$ phase. The mole concentration of a component in the vapor (gas) phase and in the oil (liquid) phase is denoted respectively as $y_{i}$ and $x_{i}$. Meanwhile, the total mole concentration of the vapor phase and the oil phase is denoted as $n_{V}$ and $n_{L}$ respectively. We then have the following relationship. $z_{i}=x_{i} n_{L}+y_{i} n_{V}$

109 The phase behavior of fluids stored in unconventional reservoirs is unlike that in conventional reservoirs. In the narrow pores of unconventional reservoirs, the capillary pressure $P_{c}$ between phases

111 can be no longer ignored [31,32]. For simplicity, in this work, the capillary pressure, which is the

112 difference between the vapor pressure $p^{V}$ and the oil phase pressure $p^{L}$, is calculated as below,

113 assuming the oil phase is the wetting phase.

$114 P_{c}=p^{V}-p^{L}=\frac{2 \sigma_{V L} \cos \theta}{r}$

115 In the above equation, $\sigma_{V L}$ is the interfacial tension between the vapor phase and the liquid phase. $\theta$ is

116 the contact angle and $r$ is the pore radius.

$117 \sigma_{V L}$ is calculated using the model from the work of Macleod [33] and Sugden [34], as follows

$\sigma_{V L}=\left(P_{a}^{L} \rho^{L}-P_{a}^{V} \rho^{V}\right)^{v}=\left(\rho^{L} \sum_{i=1}^{N_{C}} x_{i} P_{a, i}-\rho^{V} \sum_{i=1}^{N_{C}} y_{i} P_{a, i}\right)^{v}$

119 where $\rho^{L}$ and $\rho^{V}$ is the molar density of the liquid phase and the vapor phase respectively. $P_{a}^{L}$ and $P_{a}^{V}$ 120 is the parachor for the liquid phase and the vapor phase respectively. $P_{a, i}$ is the parachor of component $121 i$, the value of which is listed in Table A.2. $v$ is a parameter that is by default set to be 3.6 [35]. At the equilibrium condition, the fugacity of component $i$ in the vapor phase $f_{i}^{v}$ and in the liquid

123 phase $f_{i}^{l}$ should be equal, as

$124 f_{i}^{v}=f_{i}^{l}$

125 We introduce the fugacity coefficient of component $i$ in the vapor phase and the liquid phase, as 
$126 \quad \Phi_{i}^{V}=\frac{f_{i}^{V}}{y_{i} p^{V}}$

$127 \quad \Phi_{i}^{L}=\frac{f_{i}^{L}}{x_{i} p^{L}}$

128 Moreover, the equilibrium ratio is defined as

$129 \quad K_{i}=\frac{y_{i}}{x_{i}}=\frac{f_{i}^{V} /\left(\Phi_{i}^{V} p^{V}\right)}{f_{i}^{L} /\left(\Phi_{i}^{L} p^{L}\right)}=\frac{\Phi_{i}^{L} p^{L}}{\Phi_{i}^{V}\left(p^{L}+P_{c}\right)}$

130 By combining Equation 5 and Equation 8 and considering the constraints that $\sum_{i=1}^{N_{C}} z_{i}=\sum_{i=1}^{N_{C}} y_{i}=\sum_{i=1}^{N_{C}} x_{i}=1$,

131 we can derive the Rachford-Rice equation as

$132 \sum_{i=1}^{N_{C}} \frac{z_{i}\left(K_{i}-1\right)}{n_{L}+K_{i}\left(1-n_{L}\right)}=0$

133 In this work, Peng-Robin equation of state (PR-EOS) [36] without volume factor correction is used for

134 the calculation of the PVT properties of oil and gas. PR-EOS is a widely adopted cubic equation of

135 state. For phase $\beta$ (vapor or liquid), the compressibility can be formulated as

136

$\left(Z^{\beta}\right)^{3}+\left(B^{\beta}-1\right)\left(Z^{\beta}\right)^{2}+\left(A^{\beta}-3\left(B^{\beta}\right)^{2}-2 B^{\beta}\right) Z^{\beta}-\left(A^{\beta} B^{\beta}-\left(B^{\beta}\right)^{2}-\left(B^{\beta}\right)^{3}\right)=0 \ldots . . \beta=L, V$

137 where the term $A^{\beta}$ and $B^{\beta}$ are defined as follows

$138 \quad A^{\beta}=\frac{a_{m} p^{\beta}}{R^{2} T^{2}}$

$139 \quad B^{\beta}=\frac{b_{m} p^{\beta}}{R T}$

$140 \quad 12$

141 In the above equations, $Z^{\beta}$ is the compressibility of phase $\beta$. the terms $a_{m}$ and $b_{m}$ are defined as

142 follows as

$143 \quad a_{m}=\sum_{i=1}^{N_{C}} \sum_{j=1}^{N_{C}} z_{i} z_{j} a_{i j}$

144

145

$a_{i j}=\left(1-k_{i j}\right) \sqrt{\alpha_{i} a_{i} \alpha_{j} a_{j}}$

146

$147 a_{i}=0.45724 \frac{R^{2} T_{C_{i}}^{2}}{P_{C_{i}}}$ 
$\alpha_{i}=\left[1+S_{i}^{*}\left(1-\sqrt{T_{C_{i}} / T}\right)\right]^{2}$

$150 \quad S_{i}^{*}=0.37464+1.54226 \omega_{i}-0.26992 \omega_{i}^{2}$

$b_{m}=\sum_{i=1}^{N_{C}} b_{i}$

$b_{i}=0.0778 \frac{R T_{C_{i}}}{P_{C_{i}}}$

153 where $R$ is the gas constant. $\omega$ is the acentric factor. $k_{i j}$ is the binary interaction coefficient between component $i$ and the component j. $T_{C}$ and $P_{C}$ is the critical temperature and critical pressure respectively. The critical properties for the hydrocarbon used in this work are from NIST data [37]. The lartest root of the cubic equation is assigned to the compressibility of the vapor phase, while the smallest root is assigned to the compressibility of the liquid phase. Based on the assumption of isothermal flash calculation, in PR-EOS, the fugacity coefficients are calculated as

$\ln \left(\Phi_{i}^{\beta}\right)=\frac{b_{i}\left(Z^{\beta}-1\right)}{b_{m}}-\ln \left(Z^{\beta}-B^{\beta}\right)-\frac{A^{\beta}}{2 \sqrt{2} B^{\beta}}\left(\frac{2 \Psi_{i}}{a_{m}}-\frac{b_{i}}{b_{m}}\right) \ln \left(\frac{Z^{\beta}+(1+\sqrt{2}) B^{\beta}}{Z^{\beta}-(1-\sqrt{2}) B^{\beta}}\right)$

In the above equation, the term $\Psi_{i}$ is

$$
\Psi_{i}=\sum_{j} x_{j} \sqrt{a_{i} a_{j} \alpha_{i} \alpha_{j}}\left(1-k_{i j}\right)
$$

162 The initial guess of the equilibrium ratio $K_{i}^{0}$ is calculated by Wilson's equation

$$
K_{i}^{0}=\frac{p_{c i}}{p} \exp \left(5.37\left(1+\omega_{i}\right)\left(1-\frac{T_{c i}}{T}\right)\right)
$$

164 Initially, the capillary pressure is set to be 0.

Prior to the flash calculation, a Gibbs energy based phase stability test is performed to preliminarily determine the single phase region. The approach used here follows the work of Sherafati and Jessen [35]. The tangent plane distance (TPD) based on Michelsen's formulation [38] is as follows

169 where $\mathbf{z}$ and $\mathbf{z}_{\mathrm{T}}$ refers to the mole concentration of the feed and a trial phase, respectively. $\mu_{i}^{T}$ and $\mu_{i}^{2}$ is the fugacity of component $i$ in the trial phase and the feed respectively. $P^{T}$ and $P^{z}$ is the trial phase pressure and the reference pressure respectively. By switching the variable $\ln Z_{i}^{T}=\ln z_{i}^{T}-k$ where $k$ is the reduced value of the tangent plane distance at the stational points of Equation 23, the above equation can be expressed as 
$\operatorname{TPD}\left(\mathbf{Z}_{T}\right)=1+\sum_{i=1}^{N_{C}} Z_{T i}\left[\ln Z_{T i}+\ln \varphi_{i}^{T}+\ln P^{T}-\left(\ln Z_{i}+\ln \varphi_{i}+\ln P^{z}\right)-1\right]$

175 where $\varphi_{i}$ and $\varphi_{i}^{T}$ denotes the fugacity coefficient of component $i$ in the feed and the trial phase,

176 respectively. Finding the stationary points of TPD is equivalent to solving the below equation

$177 \quad \ln Z_{T i}+\ln \varphi_{i}^{T}+\ln P^{T}-\left(\ln z_{i}+\ln \varphi_{i}+\ln P^{z}\right)=0$

178 The above equation is iteratively solved by an accelerated direct substitution approach based on dominant eigenvalue method, as described by Orbach and Crowe [39]. It should be noticed that, unlike the phase stability test without capillary pressure, the solution of Equation 25 should take the pressure difference between the trial phase and the feed into consideration, as $P^{T}-P^{Z}= \pm P_{C}$. The sign before the capillary pressure is positive if the trial phase is the non-wetting (vapor) phase and the feed is the wetting (liquid) phase. The sign is negative if the trial phase and the feed is wetting phase and nonwetting phase respectively.

Based on the solution of the Rachford-Rich equation and the capillary pressure equation, the fugacities, as well as densities of the fluids, are obtained. The algorithm iteratively tunes the solution to minimize the residual of the equilibrium ratio as well as the capillary pressure until certain criteria are satisfied. In this work, the criterion of the convergence of the equilibrium ratio is set as

where $K_{i}^{*}$ is the equilibrium ratio solved at the previous iteration step. A flowchart of the K-value based flash calculation with capillary pressure effect is shown in Figure 1. The parameters, including binary interaction factor and parachor values, for the physical flash calculation are listed in Appendix A. As an example, the phase envelops of $\mathrm{n}-\mathrm{Decane}-\mathrm{CO}_{2}$ binary mixture with and without the capillary pressure are shown in Figure 2. Our results match well with experimental results [40]. 
Given $z, r, P, T$

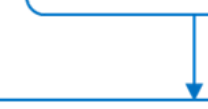

Initialization by Wilson's

equation, set $\mathrm{Pc}=0$

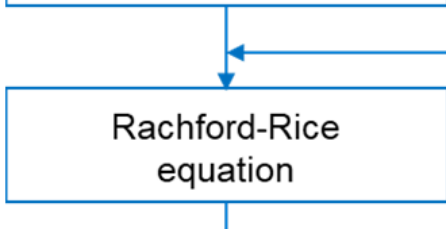

Fugacity by PR-EOS

with capillary pressure

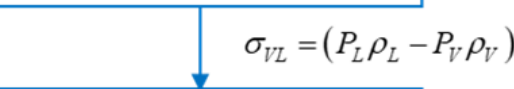

$P_{c}=p^{V}-p^{L}=\frac{2 \sigma \cos \theta}{r}$

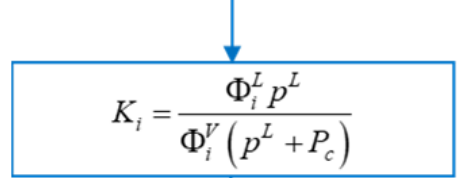

update $K$

Fugacity criteria

Figure 1 Flowchart of the K-value based flash calculation with capillary pressure effect. 


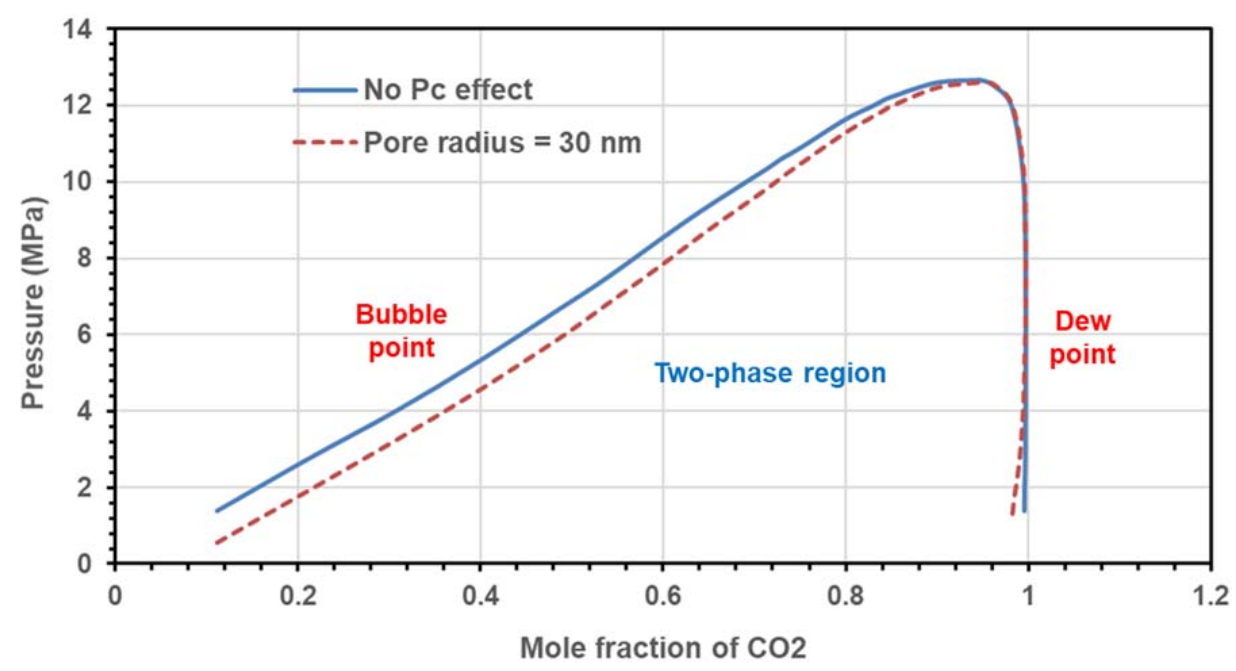

Figure 2 Phase envelop of $\mathrm{n}$-Decane- $\mathrm{CO}_{2}$ binary mixture at $71^{\circ} \mathrm{C}$.

\section{Proxy flash calculator}

\subsection{General information}

In this work, we have developed a data-driven flash calculation module based on deep learning techniques to improve the speed and convergence performance of the flash calculation in the unconventional reservoirs. In the new framework, the initial guess of the flash calculation is obtained from a stochastically trained neural network instead of Wilson's equation. We use deep-learning based stochastic training technique to develop the proxy simulator. We have trained a neural network, which has an input layer, an output layer, and four hidden layers. Within each layer, there are several neurons (elements). All neurons belonged to two neighboring layers are fully connected, as shown in Figure 3.

The neural network adopts fully connected (dense) layers and is trained as a standalone module. Once trained, the neural network predicts the phase condition, capillary pressure as well as concentration distribution by simple interpolations. As will be shown in the later chapters, the accuracy of the developed network is above $97 \%$. Therefore, a much more accurate initial guess for the flash calculation can be obtained. The fully connected layers are an imitation of human's neural system. Each element within the network has one weight value and one bias value, indicating the 'contribution' of the element. In the fully connected layers, each element is connected to all elements belonged to its neighboring layers. Activation functions are used between layers. For a given set of input parameters, the network predicts the output results by interpolating from the weight values and the bias values. During the training process, the weight and the bias of the elements are optimized by certain optimization algorithms to achieve the best prediction. Then in the prediction step as shown in Figure 4, 
223 the simulator only needs to load the trained weight and bias values into the memory and conduct 224 simple interpolation, which is very cheap in terms of computational time.

In this work, the training process consists of two steps. The first step, which is named the phase classification step, determines the phase condition of the system under the given condition. In the second step, which is named the concentration determination step, the phase ratio, component concentration, and capillary pressure are determined. The input parameters for both steps include pressure, temperature, feed concentration and pore radius. The input parameters are all normalized to $[0,1]$ scale before being substituted into the network.

Output layer

Figure 3 Conceptual model of the fully connected neural network.

Pressure, temperature, pore-radius, feed concentration

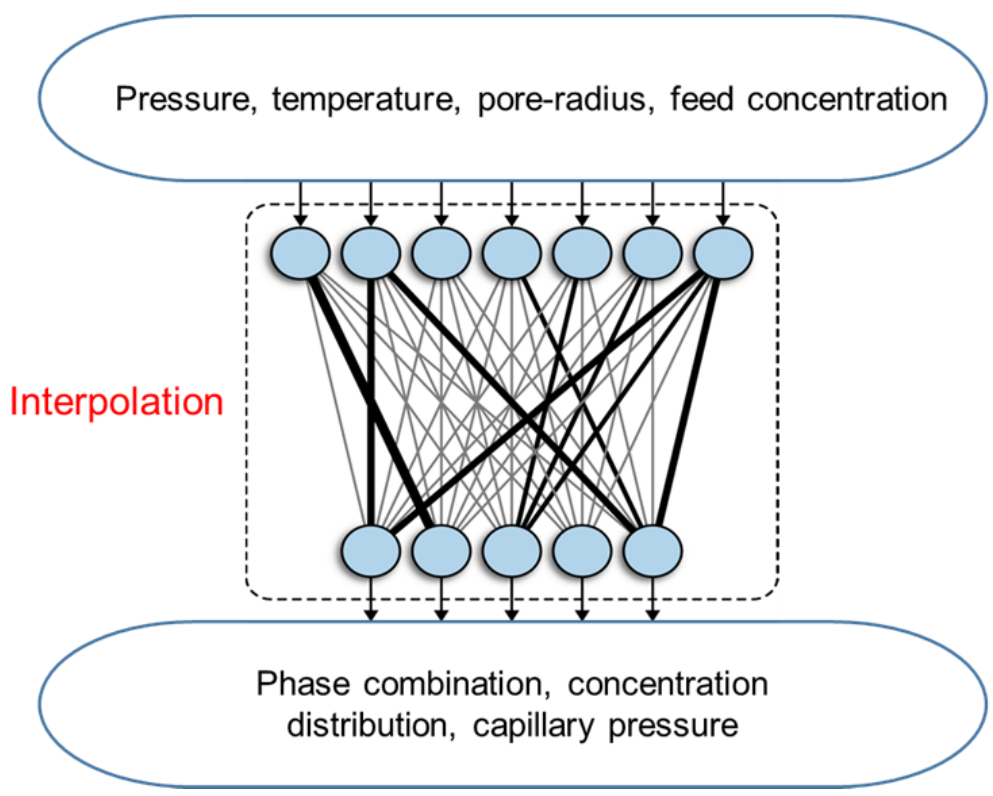




\section{3.2. Phase classification}

237 The network for the phase classification step consists of six layers, including the input layer

238 (layer 1), the output layer (layer 6) and four hidden layers (layer 2 to 5 ). The number of input

239 parameters is $N_{c}+3$. The input parameters $x$ include the feed concentration, pressure, temperature,

240 and pore radius. All input parameters are normalized to $[0,1]$ scale. The dimension of layer 1 to layer 4

241 is 64 , and the dimension of the output layer is 3 . Therefore, the network classifies the phase condition

242 into three types, namely pure vapor phase $(V)$, pure oil phase $(L)$, and double phases $(V+L)$.

$243 X=\left[P, T, r, Z_{1}, \ldots, Z_{N_{c}}\right]^{T}$

244 The activation function for layer 1 to 4 is ReLU function, as follows

$245 \operatorname{Re} L U(x)=\left\{\begin{array}{lll}0 & \text { for } & x<0 \\ x & \text { for } & x \geq 0\end{array}\right.$

246 The activation function for the output layer is Softmax function, as follows

$247 \operatorname{softmax}(x)_{j}=\frac{e^{x_{j}}}{\sum_{k=1}^{K} e^{x_{k}}}$

248 where $K$ is the total number of parameters and $\mathrm{e}^{\mathrm{x}}$ is the exponential function. A detailed structure of the network is as shown in Figure 5. 
Figure 5 Structure of the fully connected neural network for the phase classification step. The numbers refer to the dimension of the layers.

\subsection{Concentration determination}

The network for the concentration determination step consists of six layers, including the input layer (layer 1), the output layer (layer 6) and four hidden layers (layer 2 to 5). The dimension, as well as physical meanings of the input parameters of this step, are the same as those of the phase classification step. The dimension of layer 1 to layer 4 is 64 , and the dimension of the output layer is $2 N_{c}+3$, including the capillary pressure $P_{C}$, the vapor phase ratio $n_{V}$, the oil phase ratio $n_{L}$, and the component concentration in the vapor phase $y_{i}, i=1, \ldots, N_{c}$ and oil phase $x_{i}, i=1, \ldots, N_{c}$. The activation function for layer 1 to 4 is ReLU function, as shown in Equation 28. The activation function for the output layer is Sigmoid equation, as shown in Equation 30.

A detailed structure of the network is as shown in Figure 6. 


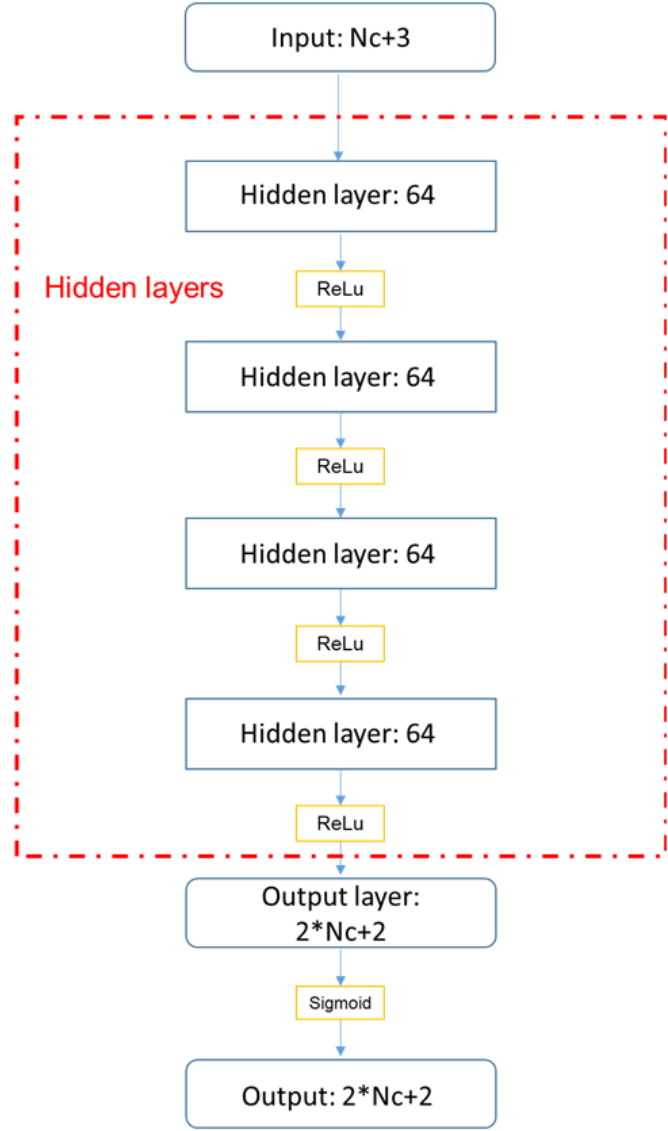

Figure 6 Structure of the neural network for the concentration determination step. The numbers refer to the dimension of the layers.

\subsection{Training}

We have investigated five cases with different combinations of hydrocarbon components. For each case, we use 300,000 training samples generated from the standalone flash calculation module described in Chapter 2. The samples are generated randomly using Latin Hypercube Sampling $[41,42]$ technique. The range of the input parameters is listed in Table 1.

Table 1 Range of the parameters of the training samples.

\begin{tabular}{|c|c|c|c|}
\hline & Unit & Minimum & Maximum \\
\hline Pressure & $\mathrm{MPa}$ & 1 & 80 \\
\hline Temperature & ${ }^{\circ} \mathrm{C}$ & 40 & 100 \\
\hline Pore radius & $\mathrm{nm}$ & 30 & 100 \\
\hline Feed concentration & dimensionless & 0 & 1 \\
\hline
\end{tabular}


280 We use stochastic gradient descent (SGD) algorithm [43] to train the network on Keras [44] with a GTX 281 1080Ti GPU of 11 GB in memory. The algorithm of SGD can be briefly described as follows (Bottou 282 2012). For an object function $Q$ with the primary variable Wof $n$ dimensions,

$283 \Theta(\mathbf{w})=\frac{1}{n} \sum_{i=1}^{n} \Theta_{i}\left(w_{i}\right)$

284 Instead of optimizing all $n$ dimensions at the same time, SGD randomly optimizes a randomly chosen group (batch) of the variables using gradient descent optimization, as below

$w_{t+1}=w_{t}-\eta \nabla_{j} \Theta\left(w_{t}\right)$

where $t$ is the number of iteration steps. $j$ is the index of a batch. $\eta$ is the learning rate. After the completion of one epoch, all the training samples are shuffled. Hence, the optimization of one highdimensional problem is effectively converted to the optimization of numerous low-dimensional problems. In this work, we have compared the choice of the learning rate. The optimal value is found to be 0.001 . The neural network for the phase classification step and the concentration determination step is trained with 100 epochs, respectively. We use the mean absolute percentage error (MAPE) as a metric (loss function) during the training, which is defined as follows.

MAPE $=\frac{100 \%}{N} \sum_{i=1}^{N}\left|\frac{A_{i}-F_{i}}{A_{i}}\right|$

In the above equation, $N$ refers to the number of testing samples. $A$ and $F$ refer to actual value and predicted (forecast) value, respectively. The accuracy of the training sample is cross validated by Kfolds approach. The training samples are randomly divided into ten groups. For every ten epochs of the training, one group is chosen for testing and the rest of the nine groups are used for training. The variation of the loss function during the training process for Case 5 is shown in Figure 7 . The error metric for each of the five cases is listed in Table 2. According to the results, the accuracy of our neural network is above $97 \%$ for the cases we run. We have compared the accuracy of the network with different number of hidden layers and found out network with four hidden layers achieves optimal performance. Generally speaking, more hidden layers (with more degree of freedom) result in deeper network and better accuracy. However, beyond a certain level the addition of more layers cannot contribute to accuracy and may even cause over-fitting issue [12]. We have also compared the performance of different activation functions for the hidden layers, including sigmoid function (as defined in Equation 30), tanh function [12] and ReLU function (as defined in Equation 28) for Case 4. The results are listed in Figure 9, which shows that ReLU function achieves the highest accuracy. However till today the choice of activation function as well as the number of layers is still like an art. Moreover, as expected when the number of hydrocarbon components increases, the accuracy decreases accordingly, due to the increase of the dimensions in the parameter space. In general, the proxy flash calculator based on deep learning techniques is much more accurate than any other 
313 existing techniques.

314

315

Table 2 Summary of errors of the fully connected network.

\begin{tabular}{ccccc}
\hline & & $\begin{array}{c}\text { Phase } \\
\text { Classification }\end{array}$ & $\begin{array}{c}\text { Concentration } \\
\text { Determination }\end{array}$ & $\begin{array}{c}\text { Overall } \\
\text { Accuracy }\end{array}$ \\
\hline $\begin{array}{c}\text { Case } \\
\text { index }\end{array}$ & Feed component & $\begin{array}{c}\text { Mean } \\
\text { Absolute } \\
\text { Percentage } \\
\text { Error }\end{array}$ & $\begin{array}{c}\text { Mean Absolute } \\
\text { Percentage } \\
\text { Error }\end{array}$ & $\begin{array}{c}\text { Mean } \\
\text { Absolute } \\
\text { Percentage } \\
\text { Accuracy }\end{array}$ \\
\hline $\mathbf{1}$ & $\mathrm{C} 1+\mathrm{C} 2+\mathrm{C} 3$ & $0.01 \%$ & $0.46 \%$ & $99.53 \%$ \\
$\mathbf{2}$ & $\mathrm{C} 1+\mathrm{C} 2+\mathrm{C} 3+\mathrm{C} 6$ & $0.02 \%$ & $0.73 \%$ & $99.25 \%$ \\
$\mathbf{3}$ & $\mathrm{C} 1+\mathrm{C} 2+\mathrm{C} 3+\mathrm{C} 4+\mathrm{C} 5$ & $0.02 \%$ & $1.02 \%$ & $98.96 \%$ \\
$\mathbf{4}$ & $\mathrm{C} 1+\mathrm{C} 2+\mathrm{C} 3+\mathrm{C} 5+\mathrm{C} 7+\mathrm{C} 9$ & $0.04 \%$ & $1.86 \%$ & $98.10 \%$ \\
$\mathbf{5}$ & $\mathrm{C} 1+\mathrm{C} 2+\mathrm{C} 3+\mathrm{C} 4+\mathrm{C} 5$ & $0.06 \%$ & $2.24 \%$ & $97.83 \%$ \\
\hline
\end{tabular}

317

318

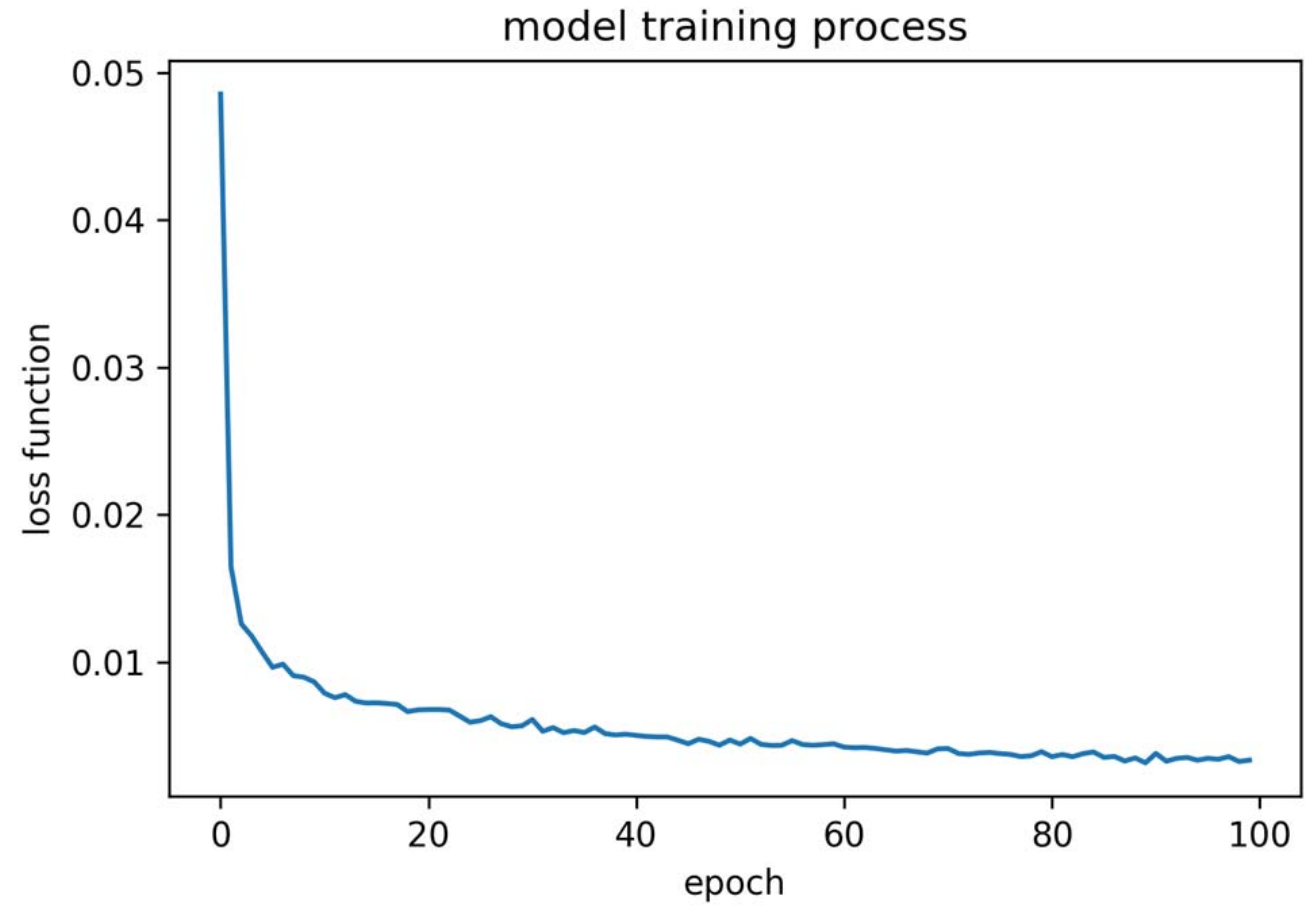

Figure 7 Variation of the loss function of the phase classification step during the training 


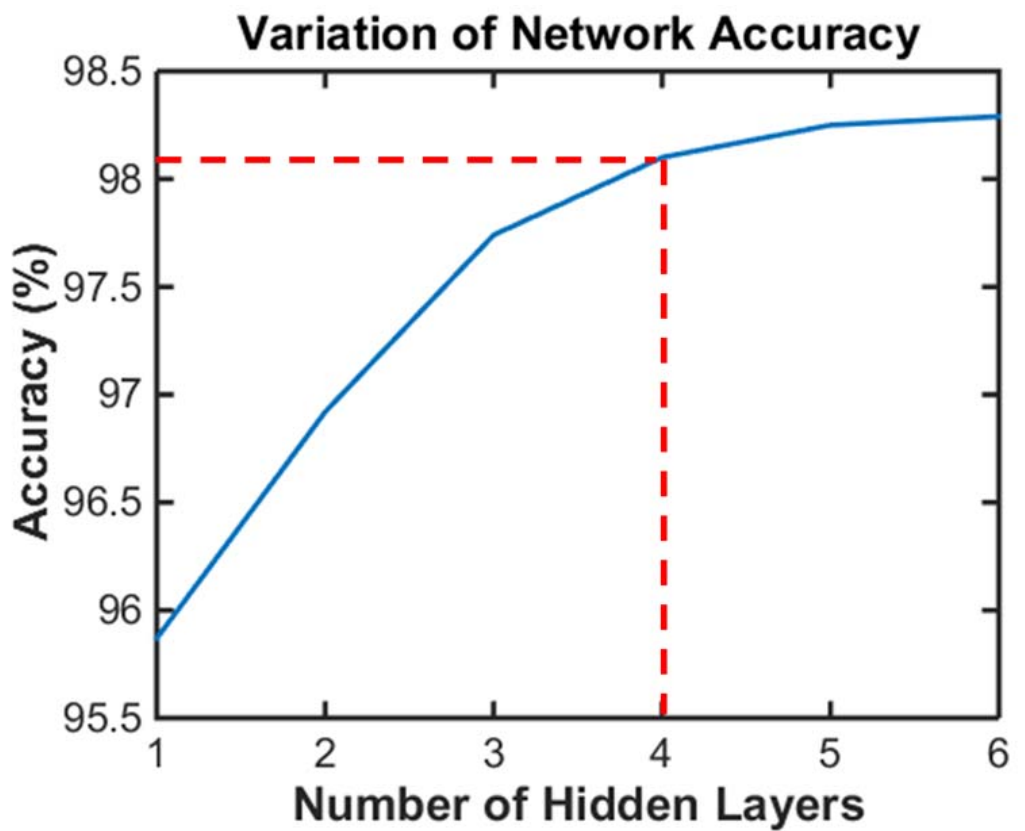

Figure 8 Comparison of the accuracy with different number of hidden layers for Case 4.

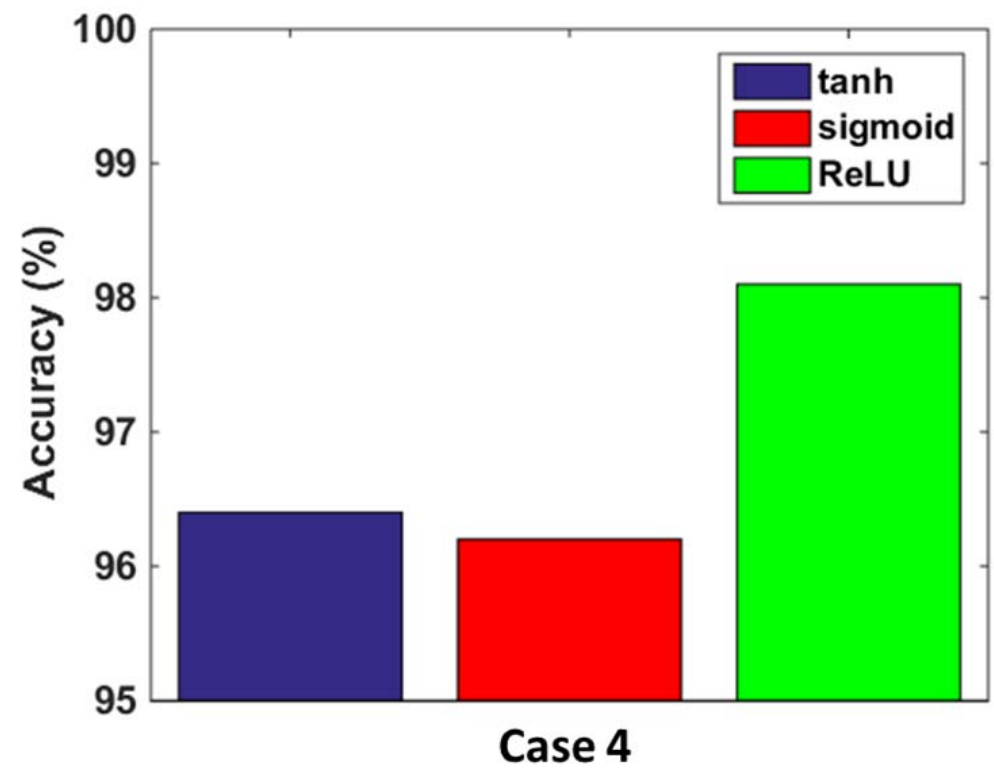

Figure 9 Comparison of the performance of different activation functions for the hidden layers in Case 4. 


\section{Deep learning based flash calculator}

The trained deep learning (DL) network is implemented in our flash calculation module. The proxy flash calculator provides the initial guess of the equilibrium ratio as well as the capillary pressure, replacing Wilson's equation. Since the phase classification step is of very high accuracy, the phase condition predicted by that step is adopted as the 'final' result. Therefore, if the phase classification step predicts that only one phase exists in the system, the DL proxy calculator directly outputs the results. If, however, the phase classification step predicts that two phases exist in the system, the flash calculator will start the K-value based iteration using the predicted equilibrium ratio and capillary pressure, until global convergence. A simplified and a detailed flowchart of the deep leaning based flash calculator are shown in Figure 10 and Figure 11 respectively.

The comparison between the average number of iterations of the flash calculation with and without DL preconditioning is shown in Table 3. According to the comparison of the numerical performance, the number of iterations has been cut by above $50 \%$. According to the results, DL based proxy calculation effectively reduces the number of iterations of flash calculation and, thus accelerates

344 the reservoir simulation.

Moreover, we have observed that DL based preconditioner effectively improves the stability 346 (convergence) of flash calculation. The large capillary effect causes the flash calculation with Wilson's 347 initial guess to be difficult to get converged, which prohibits its applications. As shown in Table 4, with 348 the implementation of the DL based preconditioner, the ratio of the converged flash calculations among 349 the 300,000 data sets (parameters shown in Table 1 ) increases from $90 \%$ to above $98 \%$. This is also 350 because that the DL based preconditioner provides a much more accurate initial guess to the flash calculation, making it close enough to the real solution for the Newton-based algorithm to converge. 


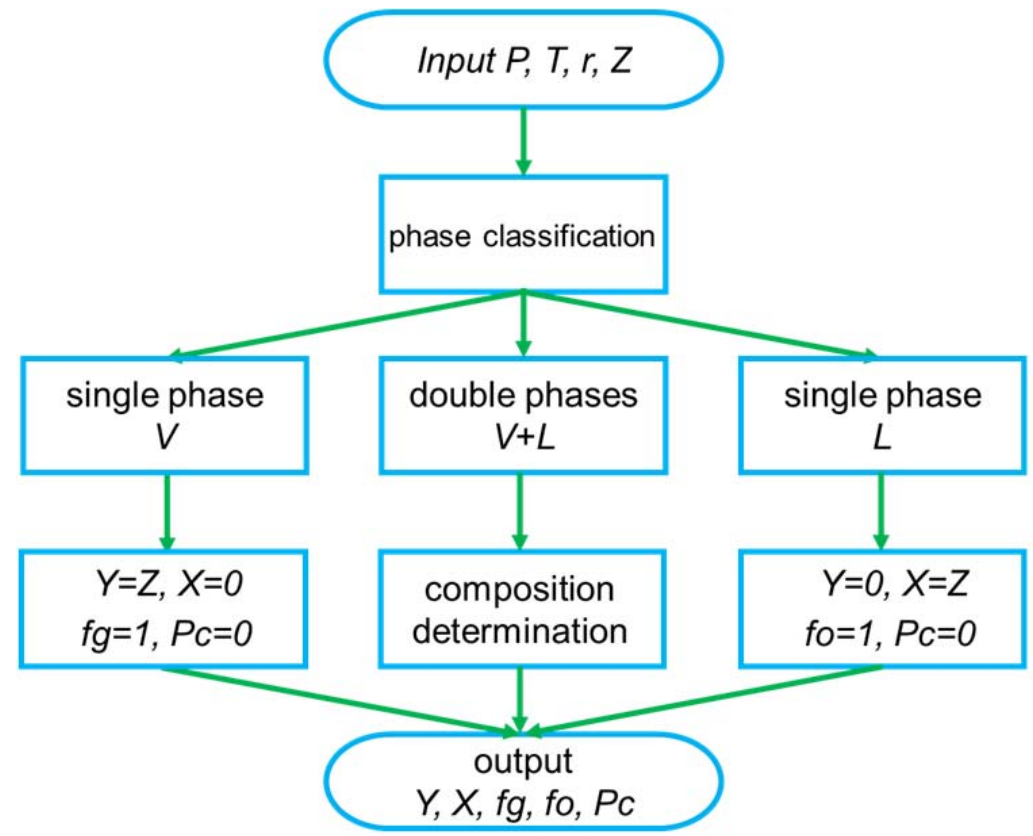




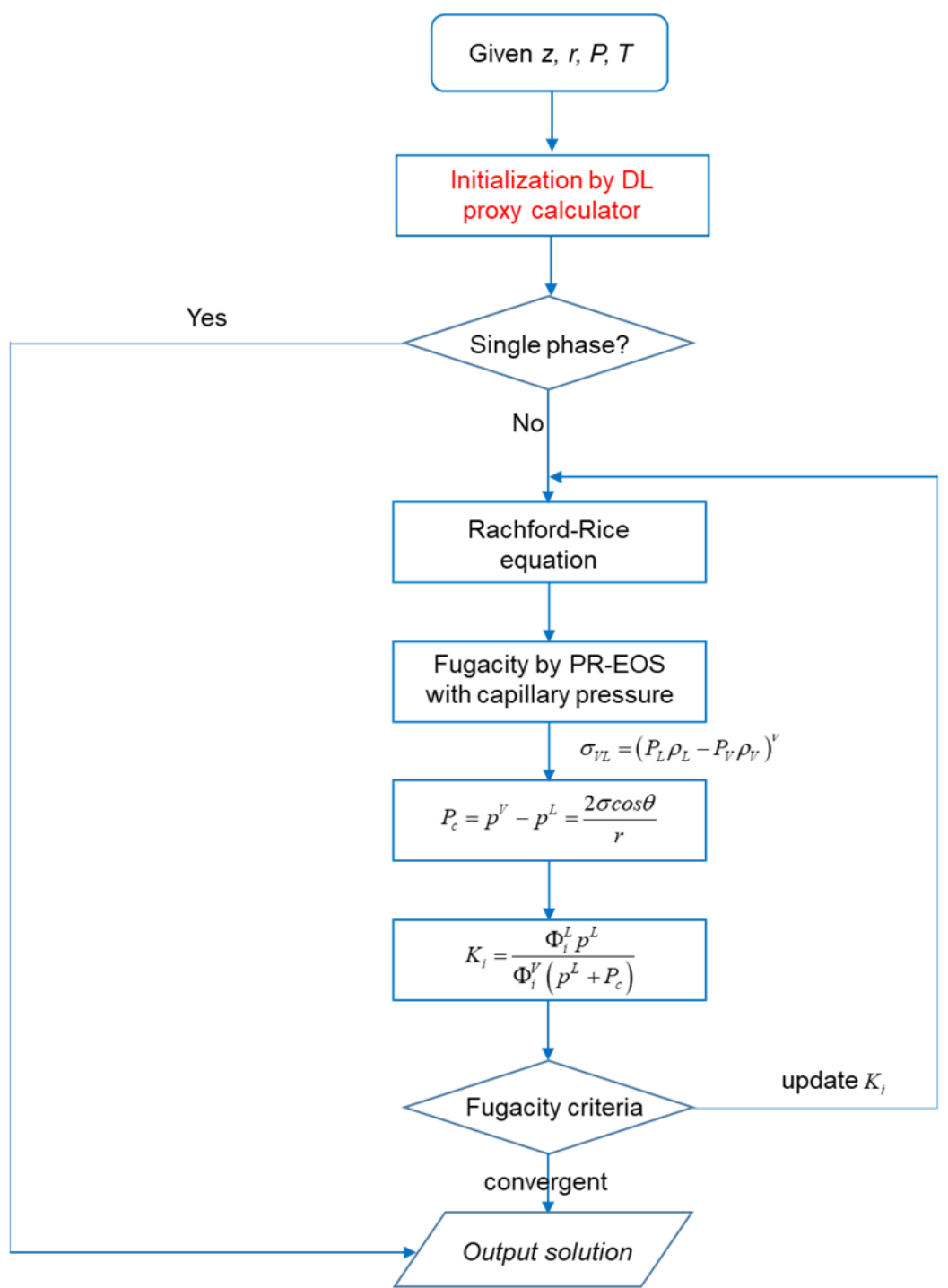

Figure 11 Flowchart of the deep leaning based flash calculator.

359

360

361

362

363

364

365

366

Table 3 Comparison of the number of iterations with and without the number of deep-learning based preconditioner.

\begin{tabular}{cccc}
\hline $\begin{array}{c}\text { Case } \\
\text { index }\end{array}$ & Feed component & $\begin{array}{c}\text { Iterations without DL } \\
\text { preconditioner }\end{array}$ & $\begin{array}{c}\text { Iterations with } \mathrm{DL} \\
\text { preconditioner }\end{array}$ \\
\hline $\mathbf{1}$ & $\mathrm{C} 1+\mathrm{C} 2+\mathrm{C} 3$ & 3.7 & 1.3 \\
$\mathbf{2}$ & $\mathrm{C} 1+\mathrm{C} 2+\mathrm{C} 3+\mathrm{C} 6$ & 8.6 & 2.0 \\
$\mathbf{3}$ & $\mathrm{C} 1+\mathrm{C} 2+\mathrm{C} 3+\mathrm{C} 4+\mathrm{C} 5$ & 14.3 & 2.2
\end{tabular}


Table 4 Comparison of the ratio of convergence with and without the number of deep-learning based preconditioner.

\begin{tabular}{cccc}
\hline $\begin{array}{c}\text { Case } \\
\text { index }\end{array}$ & Feed component & $\begin{array}{c}\text { Ratio of convergence } \\
\text { without DL preconditioner }\end{array}$ & $\begin{array}{c}\text { Ratio of convergence } \\
\text { with DL preconditioner }\end{array}$ \\
\hline $\mathbf{1}$ & $\mathrm{C} 1+\mathrm{C} 2+\mathrm{C} 3$ & $96.1 \%$ & $99.4 \%$ \\
$\mathbf{2}$ & $\mathrm{C} 1+\mathrm{C} 2+\mathrm{C} 3+\mathrm{C} 6$ & $94.9 \%$ & $99.1 \%$ \\
$\mathbf{3}$ & $\mathrm{C} 1+\mathrm{C} 2+\mathrm{C} 3+\mathrm{C} 4+\mathrm{C} 5$ & $93.4 \%$ & $98.8 \%$ \\
$\mathbf{4}$ & $\mathrm{C} 1+\mathrm{C} 2+\mathrm{C} 3+\mathrm{C} 5+\mathrm{C} 7+\mathrm{C} 9$ & $92.7 \%$ & $98.5 \%$ \\
$\mathbf{5}$ & $\mathrm{C} 1+\mathrm{C} 2+\mathrm{C} 3+\mathrm{C} 4+\mathrm{C} 5$ & $91.3 \%$ & $98.3 \%$ \\
\hline
\end{tabular}

17.0

3.6

5

$\mathrm{C} 1+\mathrm{C} 2+\mathrm{C} 3+\mathrm{C} 4+\mathrm{C} 5$

$\mathrm{C} 8+\mathrm{C} 9+\mathrm{C} 10$

\section{Ratio of convergence without DL preconditioner}

\section{with DL preconditioner}

\section{Case study}

We have implemented the deep-learning based flash calculator into our simulator MSFLOW_CO2 and have conducted several case studies to investigate the performance of the deep learning based compositional simulator. In this chapter, all numerical cases are executed by an Intel i76700 processor with $3.40 \mathrm{GHz}$. We have investigated the compositional simulation of a fractured reservoir. The reservoir is naturally fractured. A horizontal well is drilled through the reservoir, and a hydraulic fracture is engineered within the reservoir, creating a stimulated reservoir volume (SRV) in the vicinity of the hydraulic fracture. The conceptual model of the problem is shown in Figure 12, in which the green and the orange part indicates the area within and outside the SRV, respectively.

The natural fractured reservoir part and the SRV are both modeled as dual-porosity systems. In the dual-porosity system, the fracture network provides flow channel while the matrix rock stores the hydrocarbon. A 'shape-factor' [46-48] is used to quantify the flow between the matrix rock and the fracture network. Wu and Pruess [49] incorporated the shape factor into the integrated finite difference (IFD) framework. Therefore, in this work the single-continuum and dual-porosity model are both discretized using the same IFD approach, as suggested by Wu and Qin [50]. The length of the entire reservoir along $x$ - and $y$ - direction is $540 \mathrm{~m}$ and the $400 \mathrm{~m}$, respectively, while the length of the SRV along $x$-and $y$-direction is $120 \mathrm{~m}$ and $160 \mathrm{~m}$, respectively. The conceptual model of the case is shown in Figure 12 . The relative permeability of the gas phase and the oil phase is modeled by the classic 
Brooks-Corey model [51], as shown in Equation 34 and 35, where $S_{o r}$ and $S_{g r}$ refers to the residual

392 saturation of the oil and gas phase, respectively. $k_{r o, \max }$ and $k_{r g, \max }$ refer to the maximum relative

393 permeability of the oil and gas phase, respectively. $n_{o}$ and $n_{g}$ are two constants.

$394 \quad k_{r o}=k_{r o, \max }\left(\frac{S_{o}-S_{o r}}{1-S_{o r}-S_{g r}}\right)^{n_{o}}$

$k_{r g}=k_{r g, \max }\left(\frac{S_{g}-S_{g r}}{1-S_{o r}-S_{g r}}\right)^{n_{g}}$

The initial distribution of components of this case is shown in Table 5. The geomechanical impact is not considered in this case. The input parameters, including the rock properties, are listed in

398 Table 6. We run this case with three different grid block sizes, namely $10 \mathrm{~m} * 10 \mathrm{~m}, 8 \mathrm{~m} * 8 \mathrm{~m}$ and $4 \mathrm{~m} * 4$

$399 \mathrm{~m}$ for 8 years. As the results, the oil pressure fields of the fracture system and the matrix rock at the

400 end of the production are shown in Figure 13. The comparison of the oil saturation fields of the matrix

401 rock system at the end of the first year of production and at the end of the eighth year of production is

402 shown in Figure 14. According to the results, the fractures in the vicinity of the hydraulic fracture get

403 quickly drained by the production, while the pressure inside the matrix rock system declines much

404 slower. As the pressure decreases, the gas phase expands and the oil saturation decreases.

405 We compare three types of initialization strategy of the flash calculation, namely initializing by

406 Wilson's equation, initializing by the primary variable from the previous NR iteration step, and initializing

407 by the DL preconditioner. In the second type, the initial guess of the equilibrium ration of the flash

408 calculation is calculated by the primary variable of the last Newton-Raphson iteration step of the same

409 grid block. In the second, the equilibrium ratio is obtained from the deep learning based proxy flash

410 calculation module. The comparison of the CPU time of the three types with different grid block sizes is

411 shown in Figure 15. According to Figure 15, the DL preconditioner effectively reduces the CPU time by

412 about $10 \%$ to $12 \%$, compared to initializing by the equilibrium ratio from the previous iteration step. The

413 results presented in this case show that DL preconditioner is capable of accelerating the performance

414 of large scale compositional simulation for unconventional reservoirs. 


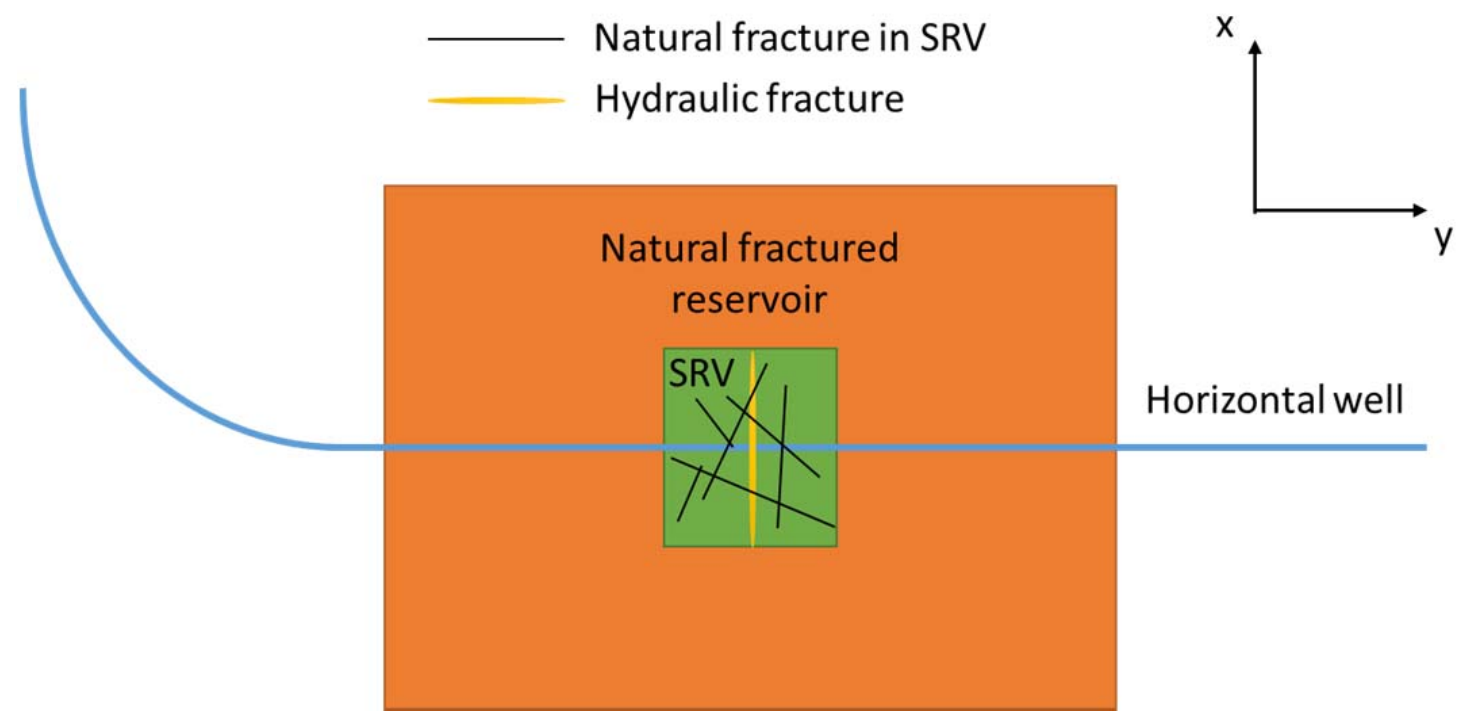

Figure 12 Conceptual model of the case study with the DL based reservoir simulator.

Table 5 Initial distribution of components for deep learning based compositional reservoir simulation case.

\begin{tabular}{lcc}
\hline Component & Formula & Mole fraction \\
\hline Methane & $\mathrm{CH}_{4}$ & 0.40 \\
Ethane & $\mathrm{C}_{2} \mathrm{H}_{6}$ & 0.15 \\
Propane & $\mathrm{C}_{3} \mathrm{H}_{8}$ & 0.15 \\
Butane & $\mathrm{C}_{4} \mathrm{H}_{10}$ & 0.05 \\
n-Pentane & $\mathrm{C}_{5} \mathrm{H}_{12}$ & 0.05 \\
n-Heptane & $\mathrm{C}_{7} \mathrm{H}_{16}$ & 0.20 \\
\hline
\end{tabular}

Table 6 Input parameters for fractured reservoir case.

\begin{tabular}{ccc}
\hline Property & Value & Unit \\
\hline Permeability of the matrix rock & 0.1 & $\mu \mathrm{d}$ \\
Porosity of the matrix rock & 0.01 & dimensionless \\
Permeability of the hydraulic fracture & 100 & $\mathrm{md}$ \\
Porosity of the hydraulic fracture & 0.2 & dimensionless \\
Permeability of the fractures in SRV & 50 & md \\
Porosity of the fractures in SRV & 0.1 & dimensionless \\
Permeability of the fractures outside SRV & 20 & md \\
\hline
\end{tabular}




\begin{tabular}{ccc}
\hline Porosity of the fractures outside SRV & 0.05 & dimensionless \\
Rock compressibility & 0.0 & dimensionless \\
Initial pressure & 21.2 & $\mathrm{MPa}$ \\
Initial temperature & 120 & ${ }^{\circ} \mathrm{C}$ \\
Production pressure & 10.2 & $\mathrm{MPa}$ \\
Pore radius & 50 & $\mathrm{~nm}$ \\
Residual gas saturation $\left(\mathrm{S}_{\mathrm{gr}}\right)$ & 0.1 & dimensionless \\
Residual oil saturation $\left(\mathrm{S}_{\mathrm{or}}\right)$ & 0.1 & dimensionless \\
Maximum gas relative permeability & 0.7 & dimensionless \\
$\left(k_{r g, \max }\right)$ & & \\
Maximum gas relative permeability & 0.9 & dimensionless \\
$\left(k_{r, \text { max }}\right)$ & & \\
$n_{g}$ & 2.0 & dimensionless \\
$n_{o}$ & 2.0 & dimensionless \\
\hline
\end{tabular}
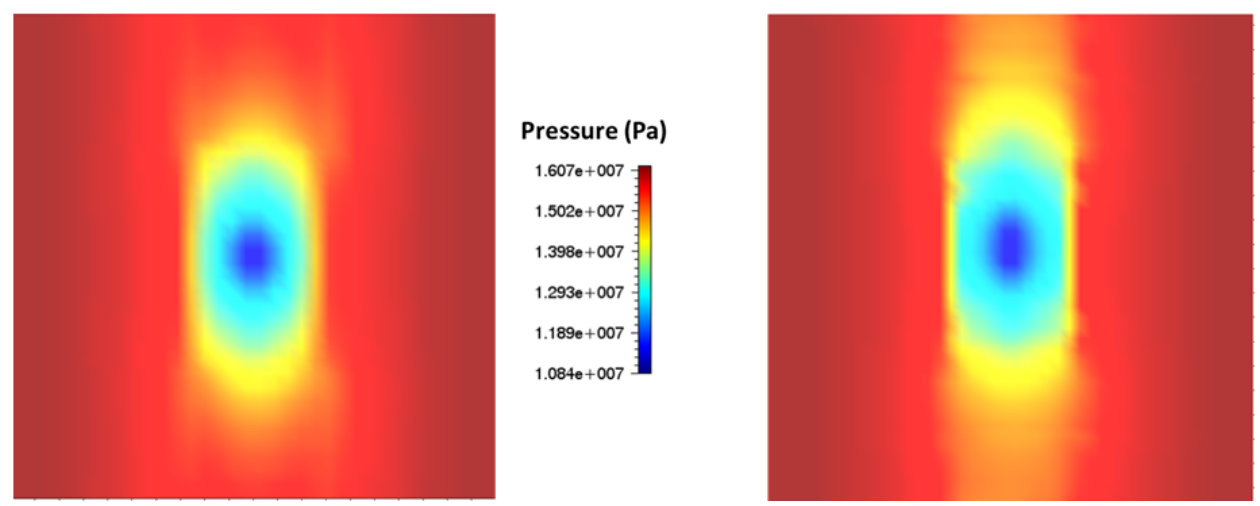


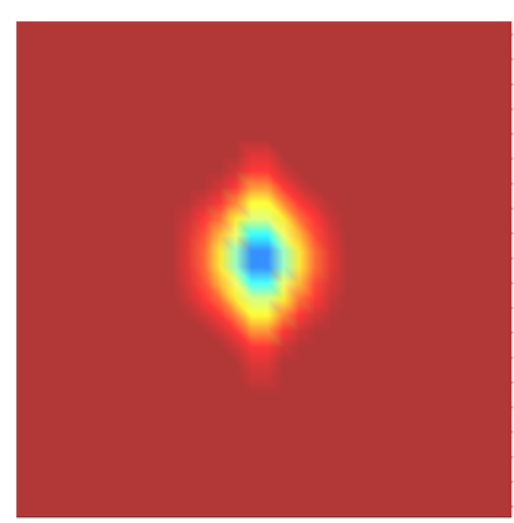

Oil Saturation
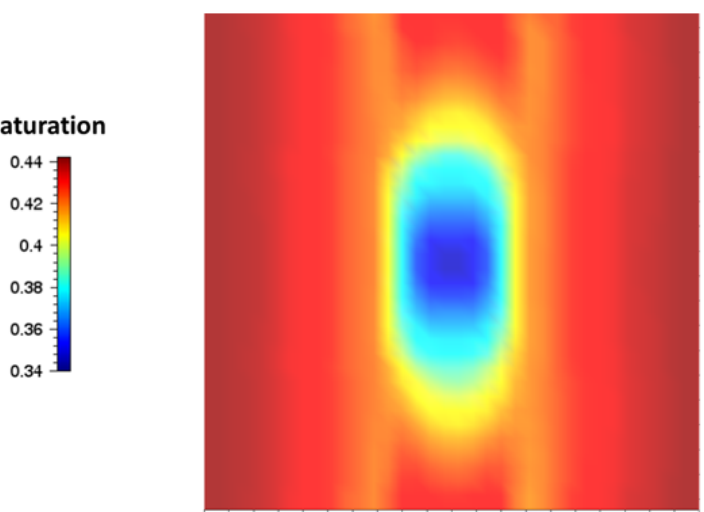

Oil Saturation

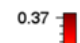

0.355

0.34

0.324

0.309

0.294

Figure 14 Comparison of the oil saturation fields of the matrix rock system at the end of the first year of production and at the end of the eighth year of production. Left: end of the first year.

Right: end of the eighth year.

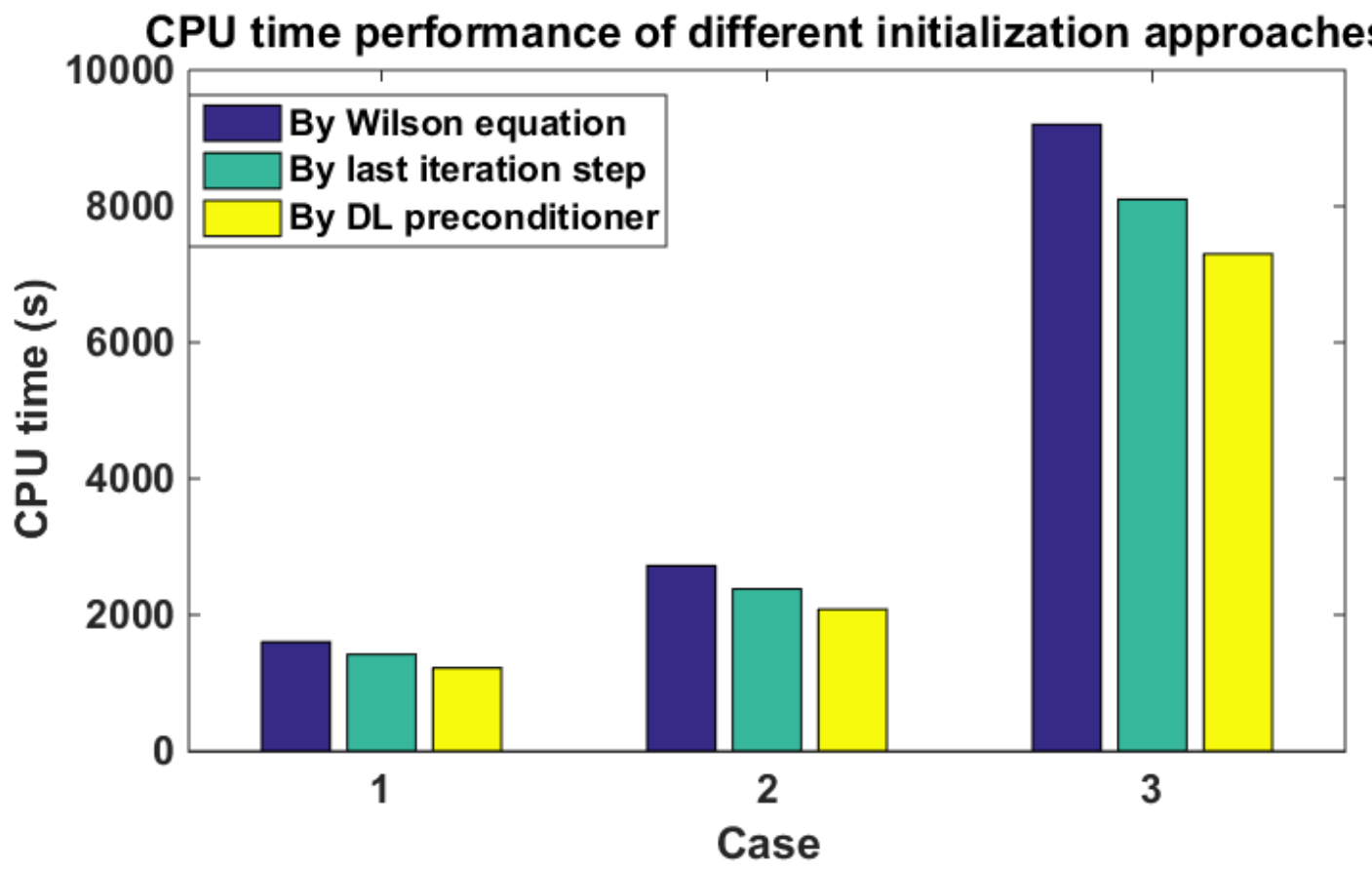

Figure 15 Comparison of the CPU time of the compositional reservoir simulation cases initialized with different initial guesses.

\section{Summary and Conclusion}

To sum up, we have developed a data-based proxy flash calculator to speed up the timeconsuming flash calculation. The proxy flash calculator adopts an initial guess obtained from the deep neural network, the accuracy of which is above $95 \%$. With the implementation of the proxy calculator, the number of iterations of the flash calculation has been effectively reduced by about $50 \%$. Moreover, the stability of the flash calculation has been improved by the DL based preconditioner, with the ratio of convergence increased from $90 \%$ to above $98 \%$ percent. This work is among the first trials in this area. 
In the present work, the fully-connected neural network is used for the proxy flash calculator. In the future, other structures can also be tried and compared, for instance, the convolutional neural network and the recurrent neural network. Moreover, other portions of the simulator may also be accelerated by the deep learning techniques. For example, the wellbore flow part, which is a very timeconsuming simulation of multiphase flow, can also be replaced by a DL based proxy calculator.

\section{Acknowledgments}

The author would like to thank Energi Simulation for their kind support.

\section{Reference}

[1] Jin B, Nasrabadi H. Phase behavior of multi-component hydrocarbon systems in nano-pores using gauge-GCMC molecular simulation. Fluid Phase Equilib 2016;425:324-34. doi:10.1016/J.FLUID.2016.06.018.

[2] Travalloni L, Castier M, Tavares FW. Phase equilibrium of fluids confined in porous media from an extended Peng-Robinson equation of state. Fluid Phase Equilib 2014;362:335-41. doi:10.1016/J.FLUID.2013.10.049.

[3] Xiong Y. Development of a compositional model fully coupled with geomechanics and its application to tight oil reservoir simulation. Colorado School of Mines. Arthur Lakes Library, 2015.

[4] Zhang Y, Lashgari HR, Di Y, Sepehrnoori K. Capillary Pressure Effect on Hydrocarbon Phase Behavior in Unconventional Reservoirs. SPE Low Perm Symp., Society of Petroleum Engineers; 2016. doi:10.2118/180235-MS.

[5] Wang S, Pomerantz AE, Xu W, Lukyanov A, Kleinberg RL, Wu Y-S. The impact of kerogen properties on shale gas production: A reservoir simulation sensitivity analysis. J Nat Gas Sci Eng 2017;48. doi:10.1016/j.jngse.2017.06.009.

[6] Kuila U, Prasad M. Understanding Pore-Structure And Permeability In Shales. SPE Annu. Tech. Conf. Exhib., Society of Petroleum Engineers; 2011. doi:10.2118/146869-MS.

[7] Wang S, Lukyanov AA, Wang L, Wu Y-S, Pomerantz A, Xu W, et al. A non-empirical gas slippage model for low to moderate Knudsen numbers. Phys Fluids 2017;29. doi:10.1063/1.4974319.

[8] Wang S, Pan Z, Zhang J, Yang Z, Wang Y, Wu Y-S, et al. On the Klinkenberg effect of multicomponent gases. Proc. - SPE Annu. Tech. Conf. Exhib., 2017.

[9] Wang S, Lukyanov AA, Wu Y-S. Second-order gas slippage model for the Klinkenberg effect of multicomponent gas at finite Knudsen numbers up to 1. Fuel 2019;235:1275-86. doi:10.1016/J.FUEL.2018.08.113.

[10] Okuno R, Johns R, Sepehrnoori K. A New Algorithm for Rachford-Rice for Multiphase 
Compositional Simulation. SPE J 2010;15:313-25. doi:10.2118/117752-PA.

[11] Nichita DV, Gomez S, Luna E. Multiphase equilibria calculation by direct minimization of Gibbs doi:10.1016/S0098-1354(02)00144-8.

[12] LeCun Y, Bengio Y, Hinton G. Deep learning. Nature 2015;521:436-44. doi:10.1038/nature14539.

[13] Gaganis V, Varotsis N. Machine Learning Methods to Speed up Compositional Reservoir Simulation. SPE Eur. Annu. Conf., Society of Petroleum Engineers; 2012. doi:10.2118/154505MS.

[14] Gaganis V, Varotsis N. An integrated approach for rapid phase behavior calculations in compositional modeling. J Pet Sci Eng 2014;118:74-87. doi:10.1016/J.PETROL.2014.03.011.

[15] Kashinath A, Szulczewski ML, Dogru AH. A fast algorithm for calculating isothermal phase behavior using machine learning. Fluid Phase Equilib 2018;465:73-82. doi:10.1016/J.FLUID.2018.02.004.

[16] Tipping, E. M. The relevance vector machine. 12th Int. Conf. Neural Inf. Process. Syst., Denver, CO: MIT Press; 1999, p. 652-8.

[17] El-Sebakhy EA. Forecasting PVT properties of crude oil systems based on support vector machines modeling scheme. J Pet Sci Eng 2009;64:25-34. doi:10.1016/J.PETROL.2008.12.006.

[18] Rafiee-Taghanaki S, Arabloo M, Chamkalani A, Amani M, Zargari MH, Adelzadeh MR. Implementation of SVM framework to estimate PVT properties of reservoir oil. Fluid Phase Equilib 2013;346:25-32. doi:10.1016/J.FLUID.2013.02.012.

[19] Burges CJC. A Tutorial on Support Vector Machines for Pattern Recognition. Data Min Knowl Discov 1998;2:121-67. doi:10.1023/A:1009715923555.

[20] Kobayashi K, Komaki F. Information criteria for support vector machines. IEEE Trans Neural Networks 2006;17:571-7. doi:10.1109/TNN.2006.873276.

[21] Schölkopf B, Smola AJ. Learning with kernels : support vector machines, regularization, optimization, and beyond. 1st ed. MIT Press; 2002.

[22] Vapnik V. The Nature of Statistical Learning Theory. 2nd ed. New York: Springer; 2000.

[23] Gharbi RB., Adel M. Elsharkawy A, Karkoub M. Universal Neural-Network-Based Model for Estimating the PVT Properties of Crude Oil Systems 1999. doi:10.1021/EF980143V.

[24] Kamyab M, Sampaio JH., Qanbari F, Eustes AW. Using artificial neural networks to estimate the Z-factor for natural hydrocarbon gases. J Pet Sci Eng 2010;73:248-57. doi:10.1016/J.PETROL.2010.07.006.

[25] Nikravesh M, Aminzadeh F, Zadeh LA. Soft computing and intelligent data analysis in oil exploration. Elsevier; 2003.

[26] Wang S. Numerical study of thermal-hydraulic-mechanical behavior of fractured geothermal 
reservoirs. Colorado School of Mines, 2015.

[27] Wu Y. MSFLOW: Multiphase Subsurface Flow Model of Oil. Gas and Water in Porous and Fractured Media with Water Shutoff Capability, Documentation and User's Guide. Walnut Creek, California: 1998.

[28] Narasimhan TN, Witherspoon PA. An integrated finite difference method for analyzing fluid flow in porous media. Water Resour Res 1976;12:57-64. doi:10.1029/WR012i001p00057.

[29] Larsbo M, Roulier S, Stenemo F, Kasteel R, Jarvis N. An Improved Dual-Permeability Model of Water Flow and Solute Transport in the Vadose Zone. Vadose Zo J 2005;4:398. doi:10.2136/vzj2004.0137.

[30] Wang S, Lukyanov AA, Wu;Yu-Shu. Application of algebraic smoothing aggregation two level preconditioner to multiphysics fluid flow simulations in porous media. SPE Reserv. Simul. Conf., Galveston, Texas: 2019.

[31] Wang L, Wang S, Zhang R, Wang C, Xiong Y, Zheng X, et al. Review of multi-scale and multiphysical simulation technologies for shale and tight gas reservoirs. J Nat Gas Sci Eng 2017;37:560-78. doi:10.1016/j.jngse.2016.11.051.

[32] Wang L, Tian Y, Yu X, Wang C, Yao B, Wang S, et al. Advances in improved/enhanced oil recovery technologies for tight and shale reservoirs. Fuel 2017;210:425-45. doi:10.1016/J.FUEL.2017.08.095.

[33] Macleod DB. On a relation between surface tension and density. Trans Faraday Soc 1923;19:38. doi:10.1039/tf9231900038.

[34] Sugden S. VI.-The variation of surface tension with temperature and some related functions. J Chem Soc, Trans 1924;125:32-41. doi:10.1039/CT9242500032.

[35] Sherafati M, Jessen K. Stability analysis for multicomponent mixtures including capillary pressure. Fluid Phase Equilib 2017;433:56-66. doi:10.1016/J.FLUID.2016.11.013.

[36] Peng D-Y, Robinson DB. A new two-constant equation of state. J Ind Fng Chem J Phys Chem Ind Fng Chem. Fundam J Agric Sci Van Stralen, S J 0. Lnt J Heat Mass Transf I O 1972;51:3851082.

[37] Lemmon, W. E. NIST Reference Fluid Thermodynamic and Transport Properties-REFPROP, Ver. 7.0. NIST Stand Ref Database 2002.

[38] Michelsen ML. The isothermal flash problem. Part I. Stability. Fluid Phase Equilib 1982;9:1-19. doi:10.1016/0378-3812(82)85001-2.

[39] Orbach O, Crowe CM. Convergence promotion in the simulation of chemical processes with recycle-the dominant eigenvalue method. Can J Chem Eng 1971;49:509-13. doi:10.1002/cjce.5450490414.

[40] Reamer HH, Sage BH. Phase equilibria in hydrocarbon systems. Volumetric and phase behavior of the n-Decane-CO ${ }_{2}$ System. J Chem Eng Data 1963;8:508-13. doi:10.1021/je60019a010. 
[41] Iman RL, Iman, L. R. Latin Hypercube Sampling. Encycl. Quant. Risk Anal. Assess., Chichester, UK: John Wiley \& Sons, Ltd; 2008. doi:10.1002/9780470061596.risk0299.

[42] Stein M. Large sample properties of simulations using latin hypercube sampling. Technometrics 1987;29:143-51. doi:10.1080/00401706.1987.10488205.

[43] Bottou L. Large-scale machine learning with stochastic gradient descent. Proc. COMPSTAT'2010, Heidelberg: Physica-Verlag HD; 2010, p. 177-86. doi:10.1007/978-3-79082604-3_16.

[44] Chollet F. Keras. 2015.

566

[45] Bottou L. Stochastic gradient descent tricks, Springer, Berlin, Heidelberg; 2012, p. 421-36. doi:10.1007/978-3-642-35289-8_25.

[46] Warren JE, Root PJ. The Behavior of Naturally Fractured Reservoirs. Soc Pet Eng J 1963;3:245-55. doi:10.2118/426-PA.

[47] Gilman JR, Kazemi H. Improvements in Simulation of Naturally Fractured Reservoirs. Soc Pet Eng J 1983;23:695-707. doi:10.2118/10511-PA.

[48] Lim KT, Aziz K. Matrix-fracture transfer shape factors for dual-porosity simulators. J Pet Sci Eng 1995;13:169-78. doi:10.1016/0920-4105(95)00010-F.

[49] Wu Y-S, Pruess K. A multiple-porosity method for simulation of naturally fractured petroleum reservoirs. SPE Reserv Eng 1988;3:327-36. doi:10.2118/15129-PA.

[50] Wu Y-S, Qin G. A generalized numerical approach for modeling multiphase flow and transport in fractured porous media. Commun Comput Phys 2009;6:85-108.

[51] Delshad M, Pope G. Comparison of the three-phase oil relative permeability models. Transp Porous Media 1989;4:59-83. doi:10.1007/BF00134742.

\section{Appendix A Parameters for flash calculation}

Table A.1 Parameters for the calculation of component properties

\begin{tabular}{|c|c|c|c|c|c|c|}
\hline & Tc (K) & $\begin{array}{c}\mathbf{P c} \\
(\mathbf{M P a})\end{array}$ & $\mathbf{w}$ & $\begin{array}{c}\mathbf{M w} \\
\left(\mathbf{g} \cdot \mathbf{m o l}^{-1}\right)\end{array}$ & $\begin{array}{c}\mathbf{a}_{\mathbf{0}} \\
\left(\mathbf{K J} \cdot(\mathbf{k g} \cdot \mathbf{K})^{-1}\right)\end{array}$ & $\begin{array}{c}\mathbf{a}_{1} \\
\left(\mathbf{K J} \cdot(\mathbf{k g} \cdot \mathbf{K})^{-1}\right)\end{array}$ \\
\hline $\mathbf{C H}_{4}$ & 190.56 & 4.599 & 0.0115 & 16.043 & 2.191 & 0.002672 \\
\hline $\mathbf{C}_{2} \mathbf{H}_{6}$ & 305.32 & 4.872 & 0.0995 & 30.07 & 1.651 & 0.004384 \\
\hline $\mathbf{C}_{3} \mathbf{H}_{8}$ & 369.83 & 4.248 & 0.1523 & 44.096 & 0.79 & 0.00468 \\
\hline $\mathbf{n}-\mathbf{C}_{4} \mathbf{H}_{10}$ & 408.14 & 3.648 & 0.2002 & 58.123 & 0.818 & 0.004255 \\
\hline $\mathbf{n}-\mathbf{C}_{5} \mathbf{H}_{12}$ & 469.7 & 3.37 & 0.2515 & 72.15 & -0.218 & 0.001895 \\
\hline
\end{tabular}




\begin{tabular}{|c|c|c|c|c|c|c|}
\hline $\mathbf{n}-\mathbf{C}_{6} \mathrm{H}_{14}$ & 507.6 & 3.025 & 0.3013 & 86.177 & -0.491 & 0.007187 \\
\hline $\mathbf{n}-\mathbf{C}_{\mathbf{7}} \mathrm{H}_{16}$ & 540.2 & 2.74 & 0.3495 & 100.204 & -0.756 & 0.007811 \\
\hline $\mathbf{n}-\mathbf{C}_{8} \mathrm{H}_{18}$ & 568.7 & 2.49 & 0.3996 & 114.231 & -0.989 & 0.00836 \\
\hline $\mathbf{n}-\mathbf{C}_{9} \mathrm{H}_{20}$ & 594.6 & 2.29 & 0.4435 & 128.258 & -1.236 & 0.008951 \\
\hline $\mathbf{n}-\mathbf{C}_{10} \mathrm{H}_{22}$ & 617.7 & 2.11 & 0.4923 & 142.285 & -1.465 & 0.009484 \\
\hline $\mathbf{C O}_{2}$ & 304.3 & 7.39 & 0.2236 & 44.01 & 0.727 & 0.003722 \\
\hline
\end{tabular}

Table A. 2 Parachor values for all hydrocarbon components

\begin{tabular}{cc}
\hline Component & Parachor \\
\hline $\mathrm{CH}_{4}$ & 77.0 \\
$\mathrm{C}_{2} \mathrm{H}_{6}$ & 108.0 \\
$\mathrm{C}_{3} \mathrm{H}_{8}$ & 150.3 \\
$\mathrm{n}-\mathrm{C}_{4} \mathrm{H}_{10}$ & 203.4 \\
$\mathrm{n}-\mathrm{C}_{5} \mathrm{H}_{12}$ & 231.5 \\
$\mathrm{n}-\mathrm{C}_{6} \mathrm{H}_{14}$ & 271.0 \\
$\mathrm{n}-\mathrm{C}_{7} \mathrm{H}_{16}$ & 312.5 \\
$\mathrm{n}-\mathrm{C}_{8} \mathrm{H}_{18}$ & 351.5 \\
$\mathrm{n}-\mathrm{C}_{9} \mathrm{H}_{20}$ & 393.0 \\
$\mathrm{n}-\mathrm{C}_{10} \mathrm{H}_{22}$ & 617.7 \\
\hline
\end{tabular}

